\title{
Science publishing in Russia 'on verge of catastrophe'
}

\begin{abstract}
Moscow. The bleak prospects facing Russian scientific publishers have become even grimmer in recent months following a series of moves by the country's chief academic publishing company, Nauka Concern. In particular, Nauka has been threatening to close its subsidiary Fizmatlit, which specializes in publishing journals and books in physics and mathematics.
\end{abstract}

The economic crisis of recent years has faced Fizmatlit with a severe decline in production which has brought it to the verge of bankruptcy. However, Fizmatlit's director, Vitaly Kulyamin, believes that ways can be found out of its current predicament.

Its prospects have been brightened by contacts with the German publishing company Verlag Harry Deutch. Fizmatlit has also signed a potentially lucrative agreement with the Foundation for Charity and

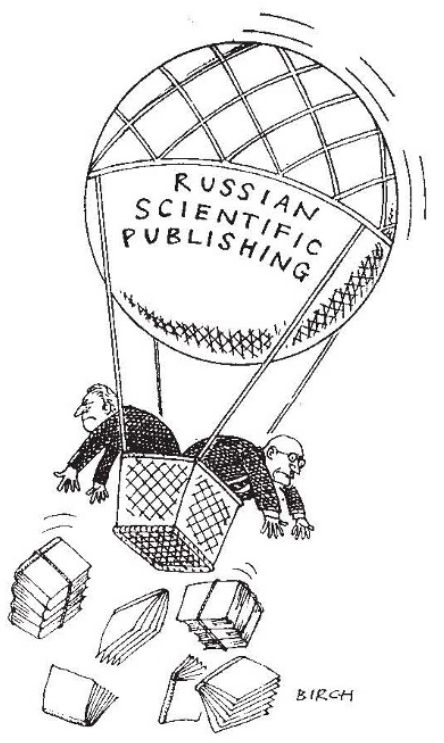

Culture, under which it plans to publish educational literature aimed at gifted children.

But during a visit to Germany in October, Vladimir Vasiliev, director of Nauka, told Fizmatlit's German partners that Fizmatlit was being closed, and that they should negotiate with him directly over any future agreements.

Only after the German company, backed by several well-known Russian academicians such as Vitaly Ginzburg, Nikita Moiseyev and the mathematician Alexander Samarsky, had expressed strong objections were the liquidation plans suspended.

Kulyamin describes Nauka's threats as a "personal conflict". But Nauka has acted in a similar way towards other parts of the organization. For example, it ordered much of the printing equipment in one of its factories to be sold at knockdown prices. The printing-works can no longer produce books, and is now able only to print letterhead and forms.

Nauka Concern is more commonly known to the Russian scientists under its old name of the Nauka Publishing House. It was created in 1964 as an amalgamation of several smaller publishing organizations and printing houses, all specializing in academic literature.

This arrangement fitted in well with the centralized Soviet system. But it became unviable with the arrival of the free market. Given the current economic crisis, scientific publishing in Russia has little chance of becoming financially profitable, and is unlikely to survive without significant outside help.

Kulyamin says that small publishing companies have a better chance of survival because of factors such as higher flexibility and lower costs. Large companies such as Nauka would have considerably more difficulty trying to survive as a scientific publisher. Some observers feel that it is preparing to transform itself into something more profitable - and less scientific.

Nauka's attempt to close down its own publishing subsidiaries has generated protests from the scientific community. "This is yet another way to devastate science in our country", says Samarsky.

The output of large publishing companies in Russia has recently diminished by, on the average, more than two thirds. The losses of scientific publishers are difficult to assess, but are probably even higher. Scientific journals are still subsidized by the state, but scientific book publishers have to struggle on their own, without even any relief from tax.

Furthermore, the Russian Foundation for Basic Research (RFBR) recently decided to cut back its support of scientific publishing, on the basis of what it claims is the gradual disappearance of those in need of such support.

Russians no longer write monographs, textbooks, or popular science literature because they are unable to find funds to support the publication of their work (publishing companies require their authors to at least cover any losses). But even when financing is made available - for example through an RFBR grant - very few people take up such an offer.

Officials at the foundation hope that a new competition for grants will stimulate greater scientific activity. But they acknowledge that the situation of book publishing in Russia is potentially catastrophic.

Vladimir Pokrovsky

\section{Brussels gives bigger role to European Science Foundation}

Strasbourg. Paolo Fasella, director-general of the European Union (EU)'s research commission, has welcomed an offer from the European Science Foundation (ESF) to play a greater role in research programmes financed through the commission in Brussels. His remarks followed a formal letter from Antonio Ruberti, the commissioner for research, to the ESF requesting more formal contact between the two bodies.

Fasella told the member organizations of the ESF attending their annual meeting in Strasbourg last week that the commission was "very positive" about using the scientific expertise of the ESF to help to evaluate research programmes, to identify referees for the programmes, and even, in certain cases, to manage some research projects.

The ESF, which runs a variety of scientific activities for its 54 member research organizations in 20 European countries, has been actively seeking stronger links with the commission (see Nature 366, 193; 1993). In particular, it wants to establish itself as a formal advisory body to the commission, representing the 'voice of science' in European-level affairs.

Some commission officials are said to have reservations, fearing that they would lose control over decision-making. But Ruberti has long been in favour of closer links with national research organizations. Last May, for example, he invited delegates from Germany, France and the United Kingdom to Brussels for formal talks.

Fasella told the ESF that the research commission needs an "independent, respected body" to advise on its proposals for scientific programmes, and that such a body could "bring regularly to the attention of political decision makers important scientific areas that may be of interest". The ESF fulfils the necessary criteria, he said.

$\mathrm{He}$ also acknowledged the difficulty the commission has always had in identifying scientific referees for its programmes, and the much criticized lack of transparency in the process. "There must now be both sein and schein", he said, implying a commitment to a system that must be both fair and seen to be fair. He foresees the ESF, with its access to national lists of potential referees, playing a fundamental role.

Fasella also said that the commission would in certain circumstances be prepared to hand over the management of commission research projects to the ESF.

But Fasella also warned that the commission will have to be convinced of the costeffectiveness of any delegation, because it is legally obliged to spend no more than five per cent of a project budget on administration. 